\title{
Treating refractory corneal hydrops in a male patient with vernal keratoconjunctivitis and mental retardation: a case report
}

\author{
En-Jie Shih ${ }^{1,2,3,4}$, Jung-Chia Lin ${ }^{5}$, Kai-Ling Peng ${ }^{1,2}$ and Jiunn-Liang Chen ${ }^{2,3^{*}}$ (])
}

\begin{abstract}
Background: Keratoconus is the most common noninflammatory bilateral corneal ectasia. Vernal keratoconjunctivitis (VKC) and eye rubbing may be associated with keratoconus in children and young adults. Timely management of advanced keratoconus is important to improve visual quality. In addition, it is challenging to carry out VKC treatment with an intent to avoid the occurrence of punctate epithelial keratitis, ulceration, or corneal neovascularization on corneal grafts.
\end{abstract}

Case presentation: We report the case of an 18-year-old male patient with a long-term history of mental retardation due to megalencephaly presenting with acute onset of corneal hydrops with prominent bulging and refractory steroid-induced glaucoma of the right eye. The topography of the right eye was unavailable due to advanced ectasia, and that of the left eye revealed central steepening with inferior-superior dioptric asymmetry. According to the clinical findings, the patient was diagnosed with keratoconus. Because of progressive corneal opacity and neovascularization, the patient underwent penetrating keratoplasty (PK) with combination of interrupted and intrastromal running suturing after receiving a preoperative subconjunctival injection of bevacizumab in his right eye, followed by lower eyelid correction. After surgery, the patient was treated with $0.1 \%$ tacrolimus dermatological ointment, $0.1 \%$ cyclosporine eye drops, artificial tears, and $0.5 \%$ loteprednol for keratoplasty and VKC. Repeated education on avoiding eye rubbing was offered to the patient. Two years after PK treatment, his best-corrected visual acuity of the right eye successfully improved from hand motion at $10 \mathrm{~cm}$ preoperatively to $6 / 20$ postoperatively.

Conclusions: Large-diameter PK with intrastromal suturing technique for advanced keratoconus could achieve better visual outcomes and avoid suture-related complications. In addition, tacrolimus dermatological ointment rather than tacrolimus topical eye drops or ointment showed satisfactory efficacy when combined with topical cyclosporine and steroid that no significant VKC reactivation were noted after PK.

Keywords: Corneal hydrops, Keratoconus, Penetrating keratoplasty, Vernal keratoconjunctivitis, Intrastromal suturing, Tacrolimus, Case report

*Correspondence: eyegogo@gmail.com

2 Department of Ophthalmology, Kaohsiung Veterans General Hospital, Kaohsiung City 81362, Taiwan

Full list of author information is available at the end of the article

\section{Background}

Keratoconus is the most common noninflammatory bilateral corneal ectasia with an incidence of 1 per 2000 in the general population without sex-based differences [1]. The comorbidities, clinical presentation, and related non-corneal and corneal disorders of keratoconus have been described in the literature [1-4]. However, only few studies have reported the histological changes and original author(s) and the source, provide a link to the Creative Commons licence, and indicate if changes were made. The images or other third party material in this article are included in the article's Creative Commons licence, unless indicated otherwise in a credit line to the material. If material is not included in the article's Creative Commons licence and your intended use is not permitted by statutory regulation or exceeds the permitted use, you will need to obtain permission directly from the copyright holder. To view a copy of this licence, visit http://creativecommons.org/licenses/by/4.0/. The Creative Commons Public Domain Dedication waiver (http://creativeco mmons.org/publicdomain/zero/1.0/) applies to the data made available in this article, unless otherwise stated in a credit line to the data. 
electron microscopic findings observed in keratoconus $[1,5,6]$.

Advanced corneal ectasia in keratoconus will deteriorate to sight-threatening complications such as corneal hydrops, corneal vascularization, or even corneal perforation, while management at these advanced stages becomes challenging without definitive guidelines. Various clinical treatment options have been reported for advanced corneal ectasia, including rigid gas permeable contact lens wearing, collagen cross-linking, and surgical approaches such as intrastromal gas injection, intrastromal corneal ring segment, keratoplasty, or wedge resection $[1,2,4,6,7]$.

\section{Case presentation}

An 18-year-old male patient visited our outpatient department with redness and pain in the right eye that lasted for 2 months. He was previously diagnosed with developmental delay, mental retardation, high myopia, and VKC accompanied by atopic dermatitis. He was presumptively treated for corneal ulcer under topical use of levofloxacin (Cravit ${ }^{\circledR}$, Santen, Osaka, Japan) and 0.1\% fluorometholone $\left(\mathrm{FML}^{\circledR}\right.$, Allergan, Dublin, Ireland) four times daily in a local clinic in his right eye. However, the patient developed quick progressive whitening and bulging of the cornea accompanied by symptoms of severe pain and photophobia. He was subsequently referred to our outpatient department for further evaluation.

At initial examination, the best-corrected visual acuity was hand motion at $10 \mathrm{~cm}$ in the right eye and $6 / 20$ in the left eye. The intraocular pressure (IOP) was $35 \mathrm{mmHg}$ in the right eye and $17 \mathrm{mmHg}$ in the left eye upon TonoPen measurement. He was noted to have lagophthalmos with proliferative changes in the tarsal conjunctiva. Slit-lamp examination showed pictures of acute corneal hydrops and dense corneal opacity with clustered neovascularization around the limbus, even without views of the anterior chamber in the right eye. Visualization of the anterior chamber and iris was obscured due to corneal opacity.

Anterior segment optical coherence tomography (OCT) findings of his right eye revealed a thickened cornea with superficial bullae and high refractivity of the entire layer (Fig. 1A). The central corneal thickness, axial length, and corneal curvature in the right eye/left eye were $2070 \mu \mathrm{m} / 587 \mu \mathrm{m}, 29.76 \mathrm{~mm} / 28.53 \mathrm{~mm}$, and nonavailable/60 D, respectively. The topography of the right eye was not available due to severe ectasia, and the left eye presented typical features of keratoconus-central steepening and inferior-superior dioptric asymmetry (Fig. $1 \mathrm{~B}$ and $\mathrm{C}$ ). The IOP was $35 \mathrm{mmHg}$ in the right eye. The IOP elevation in the right eye might have been related to marked corneal stromal edema with anterior chamber collapse or steroid-induced glaucoma. Culture tests for bacteria, viruses, and fungi were negative. The patient was finally diagnosed with advanced keratoconus with hydrops and secondary glaucoma.

Because of mental retardation and lagophthalmos, the patient was unable to cooperate in wearing a rigid contact lens. In addition, it was challenging to inject intracameral gas due to limbus-to-limbus total opacity of the cornea (the details of the iris and pupil in the anterior chamber were totally obscured). As for corneal ectasia, the corneal curvature was too severe to receive collagen cross-linking. Three days after the initial evaluation at our hospital, there was rapid progression of corneal ectasia with total opacification (Fig. 1D). Two weeks later, 360-degree peripheral corneal neovascularization was noted (Fig. 1E) with poor IOP control. The patient then received preoperative subconjunctival injection of bevacizumab (Avastin ${ }^{\circledR}$, Genentech Inc., South San Francisco, CA, US) for severe peripheral corneal neovascularization and therapeutic PK with a donor diameter of $9.5 \mathrm{~mm}$ with combination of interrupted and unique intrastromal running suturing technique (Fig. 2A and B). The technique was performed first with eight radial interrupted sutures, followed by intrastromal sutures. The needle's entry and exit points were the same to ensure that the intrastromal sutures passed over the intrastromal and deeper layers rather than the epithelial layer. Finally, the graft-host junction was strengthened using eight additional interrupted sutures (Fig. 2A and B).

Histopathological examination of the recipient cornea under light microscopy showed focal thickening with detachment of the Bowman's layer and focal vascularization of the stroma (Fig. 3A and B). Collagen fibril disarray over Bowman's layer and focal vascularization of the stroma were observed by transmission electron microscopy (Fig. 3C and D).

Postoperatively, the patient presented with a persistent paracentral shield ulcer over the corneal graft (Fig. 4A and B). The epithelial defect persisted for weeks due to refractory VKC and mild trichiasis despite aggressive lubrication. After blepharoplasty and application of $0.1 \%$ tacrolimus dermatological ointment (Protopic $^{\circledR}$, Astellas Pharma, Tokyo, Japan) on the eyelid, the shield-shaped epithelial defect healed thereafter. The postoperative IOP in the right eye was within the normal range. Eye drops of $0.1 \%$ cyclosporine (Ikervis $^{\circledR}$, Santen, Osaka, Japan) QID, 0.5\% loteprednol (Lotemax ${ }^{\circledR}$, Bausch \& Lomb, Quebec, Canada) QID, levofloxacin $\left(\mathrm{Cravit}^{\circledR}\right.$ ) QID, and artificial tears (Artelac ${ }^{\circledR}$, Bausch \& Lomb, Quebec, Canada; Duratears ${ }^{\circledR}$, Alcon Laboratories, Inc., Fort Worth, Texas, USA) 

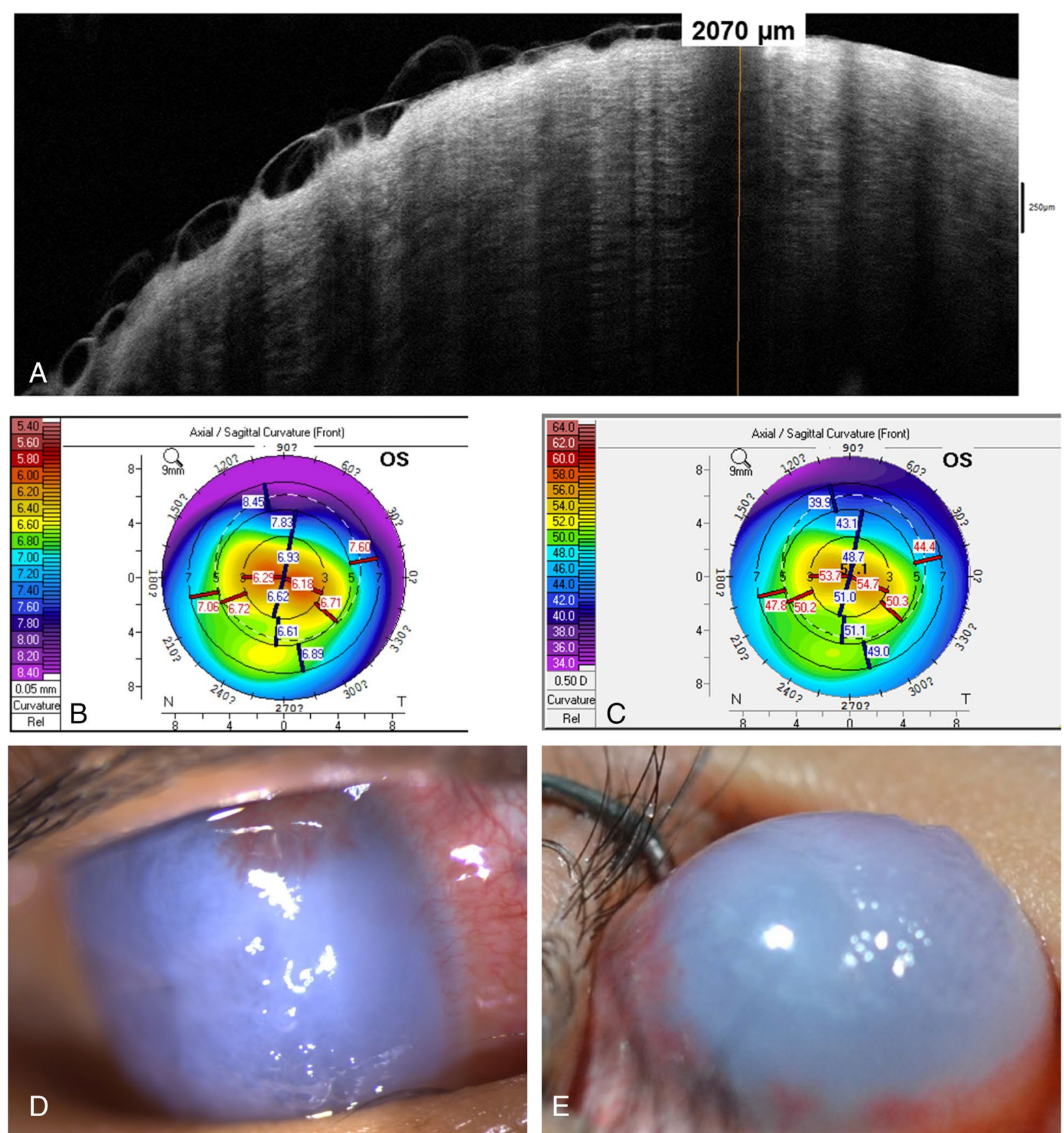

Fig. 1 Pre-PK slit-lamp photography and ASOCT of the right eye and topography of the left eye. A ASOCT image of the right eye showing corneal hydrops with severe corneal edema. B, C Topographic images of the left eye showing central steepening with inferior-superior dioptric asymmetry. D Slit-lamp photographic image demonstrating severe corneal edema, total opacity with neovascularization of the right eye from limbus to limbus, epithelial bullae, and bulging eye with extensive corneal neovascularization superiorly. E Image taken 2 weeks later shows 360-degree peripheral corneal neovascularization. PK, penetrating keratoplasty; ASOCT, anterior segment optical coherence tomography

with $0.1 \%$ tacrolimus ointment $\left(\right.$ Protopic $^{\circledR}$ ) BID over the eyelid were offered initially and tapered gradually within 18 months after surgery. The patient and his family were continuously educated on how to avoid eye rubbing. Two years after corneal transplantation, the patient's best-corrected visual acuity improved from hand motion at $10 \mathrm{~cm}$ to $6 / 20$ in the right eye, and the graft remained clear with no apparent epithelial defect (endothelial cell count, 1416; central corneal thickness, $556 \mu \mathrm{m}$ ) (Fig. 4C and D). 

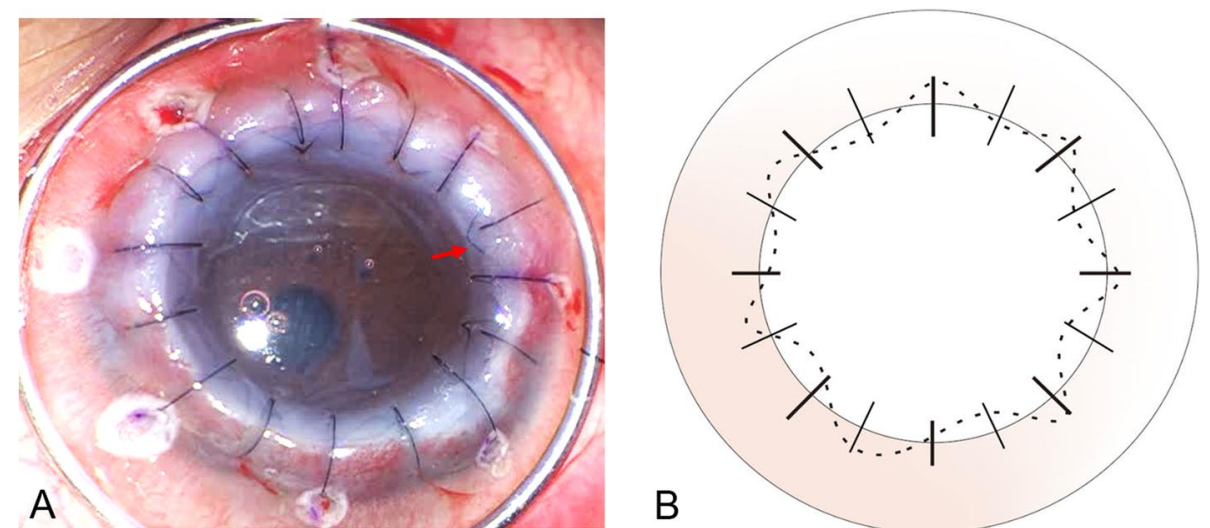

Fig. 2 The surgical image and schematic diagram of the combined interrupted and continuous intrastromal suturing in PK. A Large-diameter PK with a combination of interrupted and intrastromal running suturing (red arrow). B The technique of combined interrupted and continuous intrastromal suturing was performed first with eight radial interrupted sutures (coarse solid lines), followed by intrastromal sutures (dotted line). The needle's entry and exit points were the same to ensure that the intrastromal sutures passes over the intrastromal and deep layers rather than the epithelial layer alone. Finally, the graft-host junction was strengthened by additional eight sutures (fine solid lines). PK, penetrating keratoplasty

\section{Discussion and conclusions}

Previous studies have revealed that keratoconus coexists with comorbidities such as atopy, Down syndrome, Ehlers-Danlos syndrome, Marfan's syndrome, pseudoxanthoma elasticum, and mitral valve prolapse $[1,3,7]$. Other reports on combined ocular disorders include congenital cataracts, blue sclera, retinitis pigmentosa, and VKC $[1,3,7]$. Ectatic disorders, such as keratoconus, pellucid marginal degeneration (PMD), and keratoglobus, share overlapping ocular features with corneal protrusion, localized corneal thinning, and severe uncorrectable refractive problems. Some case reports have indicated that the natural courses of keratoconus and PMD may result in the development of keratoglobus according to a series of topographies [8, 9]. The most common type of corneal ectasia is keratoconus, which usually occurs during puberty and presents with progressively central or paracentral corneal thinning with cone-shaped protrusion. Environmental risk factors include eye rubbing and contact lens use. In our case, corneal neovascularization with acute onset of hydrops was noted as the late and progressive stage of corneal ectasia [8]. Due to VKC and trichiasis since birth, our patient, who had a history of mental retardation, kept rubbing his eyes uncontrollably and had a delay in his treatment. His corneal ectasia was compatible with extremely high myopia, irregular astigmatism, and poor vision.

Histological staining of hematoxylin-eosin in keratoconus has shown characteristics of breaks in Bowman's and Descemet's membranes [10]. Focal disruption of Bowman's layer, scarring with central or peripheral vascularization of the stroma, and unremarkable Descemet's membrane have been reported [1]. Transmission electron microscopy of corneal ectasia is uncommon. In our case, we further assessed the corneal sample under transmission electron microscopy for equivocal collagen fibril disarray in Bowman's layer and focal vascularization of the stroma, consistent with the findings reported in previous studies [5].

Treatment for mild to moderate keratoconus usually begins with the use of eyeglasses, contact lens correction, or intracameral air injection. In advanced cases, surgical intervention through keratoplasty is necessary $[1,11]$. Current keratoplasty procedures include PK, deep anterior lamellar keratoplasty, or lamellar keratoplasty with some degree of modification based on epikeratoplasty $[1,12,13]$. Ideal transplants for keratoconus ranged from $8.0-8.5 \mathrm{~mm}$ [14] to avoid larger graft-related complications of persistent epithelial defect, graft rejection, or secondary glaucoma [15]. However, the indications of large-diameter PK $(8.75-10.0 \mathrm{~mm})$ have been reported for cases with peripheral corneal pathology, such as keratoconus or PMD, to replace excised peripheral pathologic cornea and produce less astigmatism to achieve better visual outcomes [15]. In our keratoconus case, we chose a large-diameter donor cornea $(9.5 \mathrm{~mm})$ to cover the excised periphery and rescue the patient's vision.

Previous studies have reported various severities of suture-related complications and graft rejection-like reactions, including suture infiltration and loosening in keratoconus eyes, after keratoplasty [16, 17]. Keratoconus eyes with post-PK episodes of VKC reactivation further increased the rate and severity of suture-related problems, such as suture abscess and suture-tract vascularization [16]. To avoid the aforementioned complications 


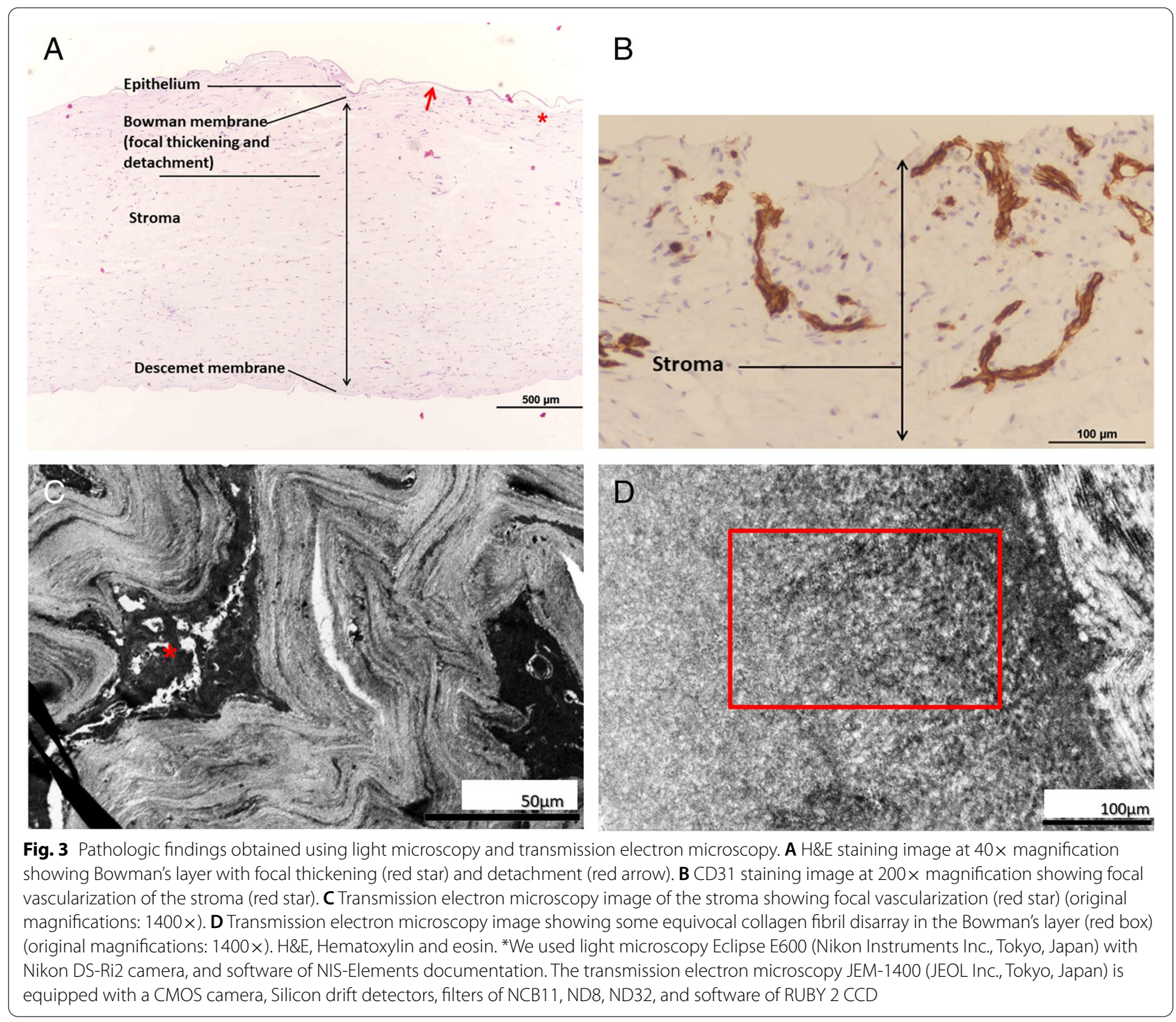

and problems that occurred in our case, we combined interrupted sutures with intrastromal suturing to bury the sutures in the corneal stromal layer without exposure. The interrupted sutures were removed 2 weeks after keratoplasty to prevent suture hypersensitivity due to the exposed suture materials. Even if all interrupted stitches are removed during the early postoperative period, intrastromal suturing is sufficient to maintain tectonic strength. A similar technique has been introduced in cataract surgery to reduce the risk of wound infection and radial keratotomy to maintain stable refraction $[18,19]$.

Topical management of VKC includes histamine receptor blockers, mast cell stabilizers, steroids, and calcineurin inhibitors (cyclosporine or tacrolimus) [20]. Tacrolimus eye drops and ointment have been reported as promising treatments for severe VKC in some European and Asian countries [21,22]. However, they are only available in certain countries; thus, topical tacrolimus dermatological ointment is another option for VKC. A recent study in Taiwan showed good efficacy of tacrolimus dermatological ointment in ten patients diagnosed with refractory VKC under two-year follow-up, in which reduced size of the papilla, improved hyperemia, and shield ulcer healing with reepithelization were noted after $0.1 \%$ tacrolimus dermatological ointment [23]. In addition, $0.05-0.1 \%$ cyclosporine eye drops have also been reported to relieve symptoms and signs such as tearing, discharge, size of the papilla, conjunctival hyperemia, and corneal neovascularization in VKC $[24,25]$. These topical agents are not only safe and effective for the treatment of VKC, but also reduce the dosage of steroids to avoid long-term side effects such as secondary glaucoma. In our case, after applying tacrolimus dermatological ointment combined with eye drops of cyclosporine, 


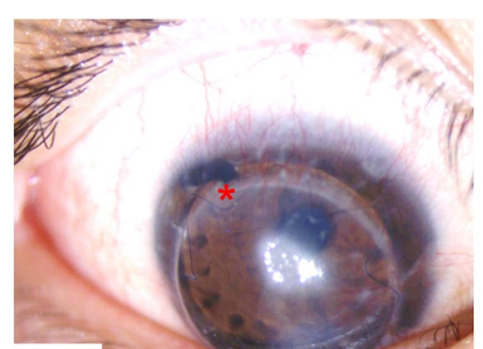

A
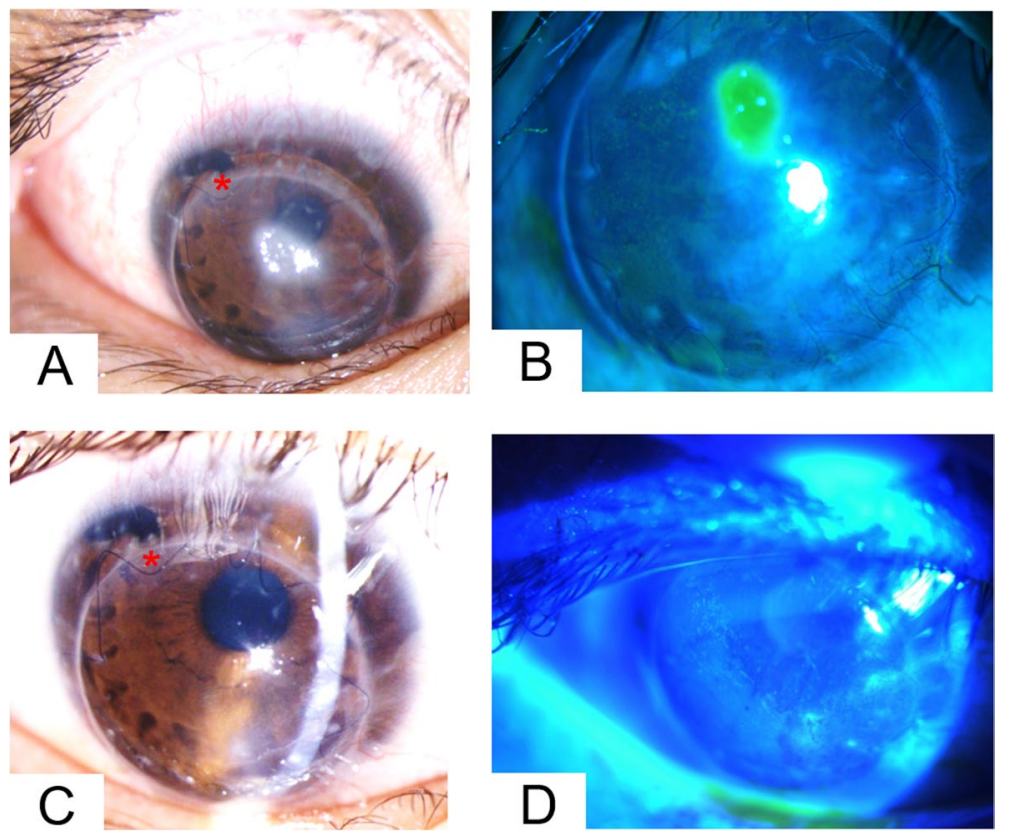

Fig. 4 Postoperative external photography of the right eye after penetrating keratoplasty. A, B Images taken at 3 months after PK showing a persistent central corneal epithelial defect with vernal keratoconjunctivitis of the right eye. C, D Images taken 6 months after PK and 3 months after epiblepharon correction showing no corneal opacity or edema. The image also shows resolved trichiasis and epithelial defect with minimal superficial punctate keratitis. No suture-related complications, such as suture infiltration and loosening were noted over our intrastromal continuous running sutures (red star). PK, penetrating keratoplasty

steroid and artificial tears postoperatively, the giant papilla became flatter without shave excision, and the shield ulcer did not recur.

Our case indicates that large-diameter PK with intrastromal running suturing technique for advanced keratoconus could achieve better visual outcomes and avoid suture-related complications. In addition, tacrolimus dermatological ointment rather than tacrolimus eye drops or ointment showed satisfactory efficacy when combined with topical cyclosporine and steroid that no significant VKC reactivation were noted after PK in our case.

\section{Abbreviations}

PMD: pellucid marginal degeneration; PK: penetrating keratoplasty; ASOCT: anterior segment optical coherence tomography.

\section{Acknowledgements}

Not applicable.

\section{Authors' contributions}

EJS collected the clinical data, captured images, and drafted and revised the manuscript. JCL offered and interpreted the pathological images of the patient, and revised the manuscript. KLP revised the manuscript. JLC was responsible for the clinical treatment of the patient, editing the patient's images, and revising the manuscript. All authors read and approved the final manuscript.

\section{Funding}

Not applicable.

\section{Availability of data and materials}

All data generated or analyzed during this study are included in this published article.

\section{Declarations}

Ethics approval and consent to participate

We informed the patient and his parents about the risks and benefits of penetrating keratoplasty and correction of trichiasis. The patient's parents signed the consent form for the operation after fully understanding the details of the procedure.

\section{Consent for publication}

Written informed consent was obtained from the patient and his parents for publication of this case report and any accompanying images.

\section{Competing interests}

The authors declare that they have no competing interests.

\section{Author details \\ ${ }^{1}$ School of Medicine, National Yang Ming Chiao Tung University, Hsinchu, Tai- wan. ${ }^{2}$ Department of Ophthalmology, Kaohsiung Veterans General Hospital, Kaohsiung City 81362, Taiwan. ${ }^{3}$ School of Medicine, Kaohsiung Medical Uni- versity, Kaohsiung, Taiwan. ${ }^{4}$ Chung Shan Medical University, Taichung, Taiwan. ${ }^{5}$ Department of Pathology and Laboratory Medicine, Kaohsiung Veterans General Hospital, Kaohsiung, Taiwan.}

Received: 18 June 2021 Accepted: 30 December 2021

Published online: 24 January 2022 


\section{References}

1. Rabinowitz YS. Keratoconus. Surv Ophthalmol. 1998;42:297-319.

2. Krachmer JH, Feder RS, Belin MW. Keratoconus and related noninflammatory corneal thinning disorders. Surv Ophthalmol. 1984;28:293-322.

3. Hashemi H, Heydarian S, Hooshmand E, Saatchi M, Yekta A, Aghamirsalim $\mathrm{M}$, et al. The prevalence and risk factors for keratoconus: a systematic review and Meta-analysis. Cornea. 2020:39:263-70.

4. Imbornoni LM, McGhee CNJ, Belin MW. Evolution of keratoconus: from diagnosis to therapeutics. Klin Monatsbl Augenheilkd. 2018;235:680-8.

5. Sawaguchi S, Fukuchi T, Abe H, Kaiya T, Sugar J, Yue BY. Three-dimensional scanning electron microscopic study of keratoconus corneas. Arch Ophthalmol. 1998; 116:62-8.

6. Maharana PK, Dubey A, Jhanji V, Sharma N, Das S, Vajpayee RB. Management of advanced corneal ectasias. Br J Ophthalmol. 2016;100:34-40.

7. Mukhtar S, Ambati BK. Pediatric keratoconus: a review of the literature. Int Ophthalmol. 2018;38:2257-66.

8. Cameron JA. Keratoglobus Cornea. 1993;12:124-30.

9. Karabatsas $\mathrm{CH}$, Cook SD. Topographic analysis in pellucid marginal corneal degeneration and keratoglobus. Eye (Lond). 1996;10(Pt 4):451-5.

10. Fernandes BF, Logan P, Zajdenweber ME, Santos LN, Cheema DP, Burnier MN Jr. Histopathological study of 49 cases of keratoconus. Pathology. 2008;40:623-6.

11. Wallang BS, Das S. Keratoglobus. Eye (Lond). 2013;27:1004-12.

12. Alio Del Barrio JL, Al-Shymali O, Alio JL. Femtosecond laser-assisted tuckin penetrating keratoplasty for advanced keratoglobus with endothelial damage. Cornea. 2017;36:1145-9.

13. Jarade E, Antonios R, El-Khoury S. Limbal stem cell-sparing corneoscleroplasty with peripheral intralamellar tuck: a new surgical technique for keratoglobus. Case Rep Ophthalmol. 2017:8:279-87.

14. Seitz B, Langenbucher A, Hager T, Janunts E, El-Husseiny M, Szentmary N. Penetrating Keratoplasty for keratoconus - excimer versus femtosecond laser trephination. Open Ophthalmol J. 2017;11:225-40.

15. Skeens HM, Holland EJ. Large-diameter penetrating keratoplasty: indications and outcomes. Cornea. 2010;29:296-301.

16. Feizi S, Javadi MA, Moshtaghion SM, Abolhosseini M. Comparison of penetrating keratoplasty and deep anterior lamellar keratoplasty in keratoconus eyes with vernal keratoconjunctivitis. Ther Adv Ophthalmol. 2021:13:25158414211010551.

17. Hirano K, Tanaka H, Kato K, Araki-Sasaki K. Graft rejection-like reactions in the early postoperative period after deep anterior lamellar keratoplasty for keratoconus: a retrospective study. Clin Ophthalmol. 2018;12:2315-22.

18. Chipont Benabent E, Artola Roig A, Martinez Toldos JJ. Intrastromal corneal suture for small incision cataract surgery. J Cataract Refract Surg. 1996:22:671-5.

19. Lyle WA, Jin GJ. Long-term stability of refraction after intrastromal suture correction of hyperopia following radial keratotomy. J Refract Surg. 1995;11:485-9.

20. Singhal D, Sahay P, Maharana PK, Raj N, Sharma N, Titiyal JS. Vernal keratoconjunctivitis. Surv Ophthalmol. 2019;64:289-311.

21. Fukushima A, Ohashi Y, Ebihara N, Uchio E, Okamoto S, Kumagai N, et al. Therapeutic effects of $0.1 \%$ tacrolimus eye drops for refractory allergic ocular diseases with proliferative lesion or corneal involvement. $\mathrm{Br} J$ Ophthalmol. 2014:98:1023-7.

22. Pucci N, Caputo R, di Grande L, de Libero C, Mori F, Barni S, et al. Tacrolimus vs. cyclosporine eyedrops in severe cyclosporine-resistant vernal keratoconjunctivitis: a randomized, comparative, double-blind, crossover study. Pediatric allergy and immunology: official publication of the European Society of Pediatric Allergy and Immunology. 2015;26:256-61.

23. Liu FY, Liu HY, Chu HS, Chen WL, Hu FR, Wang IJ. Dermatologic tacrolimus ointment on the eyelids for steroid-refractory vernal keratoconjunctivitis. Graefes Arch Clin Exp Ophthalmol. 2019;257:967-74.
24. Yücel OE, Ulus ND. Efficacy and safety of topical cyclosporine a $0.05 \%$ in vernal keratoconjunctivitis. Singap Med J. 2016;57:507-10.

25. Nebbioso M, Alisi L, Giovannetti F, Armentano M, Lambiase A. Eye drop emulsion containing $0.1 \%$ cyclosporin $(1 \mathrm{mg} / \mathrm{mL}$ ) for the treatment of severe vernal keratoconjunctivitis: an evidence-based review and place in therapy. Clin Ophthalmol. 2019;13:1147-55.

\section{Publisher's Note}

Springer Nature remains neutral with regard to jurisdictional claims in published maps and institutional affiliations.
Ready to submit your research? Choose BMC and benefit from:

- fast, convenient online submission

- thorough peer review by experienced researchers in your field

- rapid publication on acceptance

- support for research data, including large and complex data types

- gold Open Access which fosters wider collaboration and increased citations

- maximum visibility for your research: over $100 \mathrm{M}$ website views per year

At $\mathrm{BMC}$, research is always in progress.

Learn more biomedcentral.com/submissions 